\title{
Opportunities from the COVID-19 Pandemic: Being Greener through Online and E-Learning Methods
}

\author{
Diana Chalil ${ }^{1, *}$, Riantri Barus ${ }^{2}$ \\ ${ }^{1,2}$ Universitas Suumatera Utara, Jl. Dr Mansur No 9, Medan, Indonesia \\ *corresponding author: chalildiana@gmail.com
}

\section{Article Info}

Received:

15 March 2021

Accepted:

25 May 2021

Published:

1 August 2021

DOI:

Presented in The $6^{\text {th }}$ International (Virtual) Workshop on UI GreenMetric World University Rankings (IWGM 2020)

\begin{abstract}
To implement physical distancing during the COVID-19 pandemic, many universities around the world have applied online and Elearning methods. Although faced with several obstacles, online and Elearning methods also provide many opportunities. One of them include the reduction of paper usage, which in 2019 totaled to 394 million tons worldwide. To analyze such an opportunity, this study was conducted at Universitas Sumatera Utara (USU) by involving 232 students and 113 lecturers from 16 faculties. Data were obtained using a structured online questionnaire. The results show that paper usage at USU can be reduced through online and e-learning methods by $48,008,800$ sheets per year or equivalent with approximately 4,003 trees. This amount is totalled from lecturer research activities, lecture materials, and student final projects, which are $240,000,44,800,000$ and 3,000,000 sheets, respectively. To realize this, USU is required to improve internet facilities and e-learning access, train lecturers and students to use and manage said facilities, and train lecturers to prepare materials specifically designed for online and elearning.
\end{abstract}

\section{Keyword:}

reducing paper usage, e-learning, COVID-19

\section{Introduction}

According to [1], although slowly decreasing, paper production still contributes to deforestation. The global paper consumption is recorded at more than 400 million metric tons per year. The biggest contributors are packaging and tissue products, however printing and writing papers are also considered high deforestation risk products as they contain only $8 \%$ recycled content. China and the United States are currently the highest paper consuming countries, contributing to more than $40 \%$ of the global paper consumption. Surprisingly, EU countries are also among the top ten paper consuming countries. Indonesia is not among this group, but is unfortunately one of the biggest pulp producer and still often accused as being among the massive causes of carbon emission. 
Such a condition is suddenly changed during the COVID-19 pandemic. The need for physical distancing has forced schools and universities to utilize digital learning and remote work. This has caused the United States and Japan (as the second and third largest paper consumers) to decrease their paper consumption by approximately $30 \%$ and $20 \%$, respectively [2]. Furthermore, e-learning can also save money and increase awareness regarding sustainability and energy conservation. Although triggered by a big shock with a relatively long uncertain period, such a condition could provide opportunities to reduce paper usage and avoid further deforestation. Because education is critical in reducing environmental degradation, the United Nations declared 2005-2014 as the UN Decade of Education for Sustainable Development. Ironically, [3] reported that the most educated citizens in the world's most industrialized nations tend to be the worst offenders of global sustainability, as they use the most resources. Unfortunately, many teachers and lecturers are likely not competent enough to utilize digital learning. Suprisingly, a handful of computer-literate students also face difficulties in the process of digital learning. Other issues include those related to facilities, namely internet connection and gadget ownership. These issues should be addressed immediately so as to avoid marginalization. Technical and institutional issues are easier to address than patron behavior [4]. However, all of these aspects are equally important.

This study was conducted at Universitas Sumatera Utara (USU) to analyze the benefits and probabilty of maintaining and optimizing the e-learning method in universities, which at the end is hoped to reduce deforestation. Since the national COVID-19 pandemic warning in March 2020, USU has been issuing policies and improving facilities to support the E-learning process. This includes the Rector Circular Letter regarding the implemenattion of E-Learning during the COVID-19 pandemic, the improvement of USU bandwith and internet connection, unlimited internet access, 24/7 IT monitoring, the SOP of the mailing system and webinar applications.

\section{Methods}

This study was conducted in Universitas Sumatera Utara, involving more than 40,000 students with several improvements to support e-learning. Data were obtained from 113 lecturers and 232 students from 16 faculties at USU, which consist of undergraduate and graduate students. Lecturers and students who mostly engage in supervisions for final projects are purposively selected. The survey was conducted online through a googleform questionnaire from May to August 2020. There were 3 analyzed activities that were directly related to the use of paper in relatively large quantities and could be directly regulated by policy makers at USU, namely lectures, thesis advising and lecturer research. Descriptive statistics were utilized to analyze the quantitative data from the survey. Content analysis was utilized to analyze the open-ended questions.

\section{Results and Discussion}

The questionnaire results showed that almost all respondents stated that lectures and thesis advising were conducted face-to-face before the COVID-19 pandemic. Only about 5\% stated that activities were combined with online methods, specifically thesis advising involving one-on-one interactions between lecturers and students. This is mainly to ease schedule arrangement between lecturers and students, which is relatively simple to arrange in one-on-one interactions. 


\subsection{Paper Usage in Face-to-Face Activities}

\subsubsection{Survey results from lecturer samples}

- Lectures

Survey results showed that according to lecturer samples, paper usage in face-to-face activities range between 2-7000 sheets (left picture). However, by removing outliers it can be estimated that the average paper usage is around 118.06/person/subject. Lecture materials, especially those in the form of PowerPoint, are also shared through the class president via emails, Whatsapp or blogs. During the COVID-19 pandemic, lectures are conducted online and have practically reduced paper usage. Various online methods are used, including Google Classroom, Google Meet, Zoom, Skype, Whatsapp, email and an elearning system built by USU before the pandemic. Some have also utilized videos, e-books and online articles from the internet. Most respondents combine 2-4 applications, but 56\% only utilize 1 application.
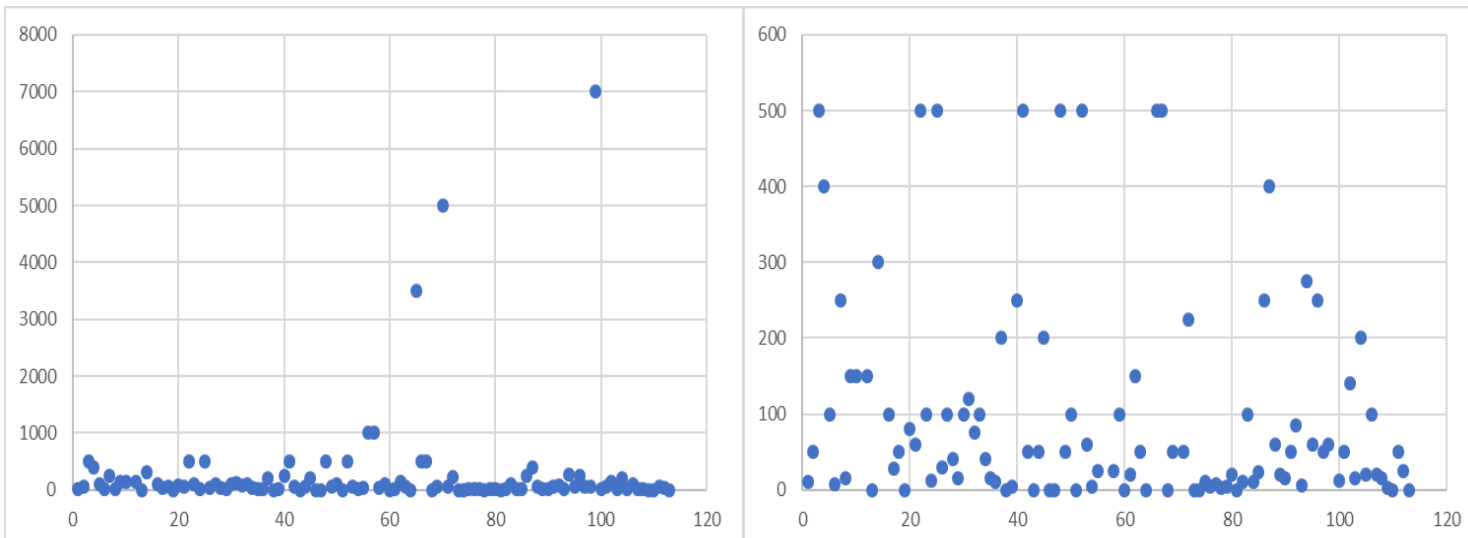

Figure 1. Paper usage (left: all samples, right: outlier removal) in face-to-face activities

\section{- Thesis completion}

Although few and far between, in the process of thesis writing there have been several lecturers who combine face-to-face and online methods before the work from home (WFH) policy was implemented. Since the implementation of WFH, thesis advising has been carried out using online methods with similar media as in lectures.

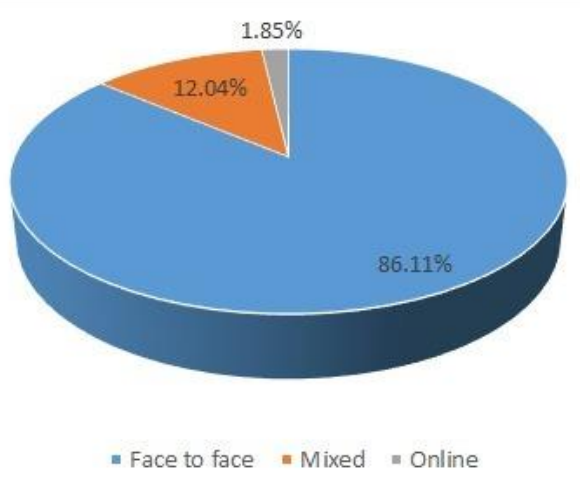

Figure 2. Thesis advising methods pre-WFH

\section{- Research}

Research is one of the three pillars of higher education with a high paper usage, especially in reports. The results of the interviews show that on average, 1 research title 
required 18 copies of reports from porposal, revised proposal, progress report, $70 \%$ financial report, final report and 30\% financial report. Each needs 3 copies with an average page count of 53 pages.
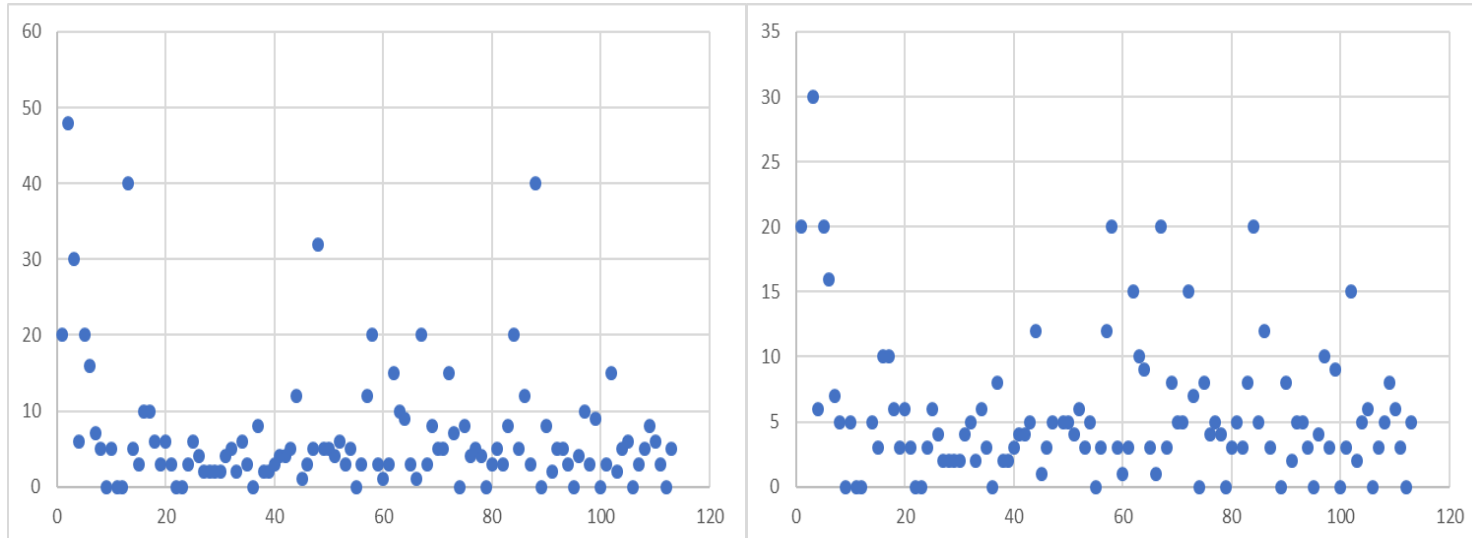

Figure 3. Number of reports for each research title conducted by lecturers (left: all samples, right: outlier removal)
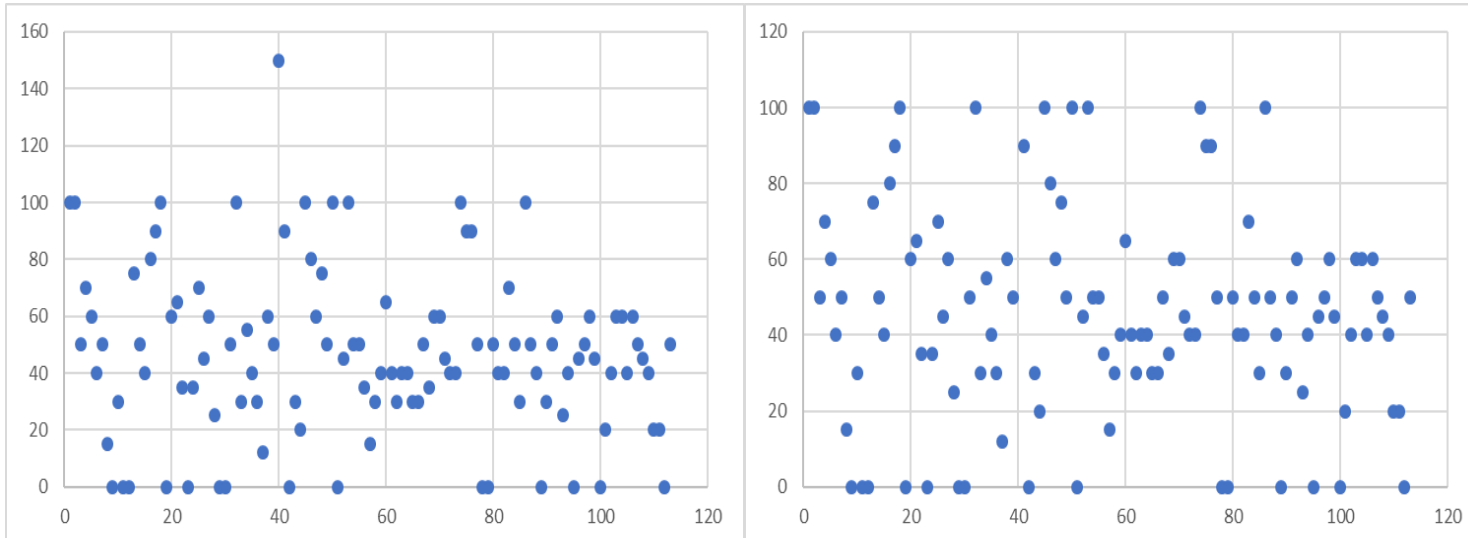

Figure 4. Number of pages for each research report written by lecturers (left: all samples, right: outlier removal)

The research conducted by USU lecturers is not entirely sourced from USU talenta grants, so the terms also vary. However, as focus of the analysis is those directly subject to the internal/under control of USU policies, therefore this study mostly choose the talent grant. From 2018-2020, USU funded 733 titles each year. Reports submitted in hard copy include 3 copies of each proposal, revised proposal, progress report, $70 \%$ finance report, final report, and $30 \%$ finance report, with a total of 18 reports for each title.

With an average 53 sheets per report, 699,282 (18 x $53 \times 733)$ sheets of paper are needed per year. Currently, even though the proposal and reports are submitted through the system, the lecturer must still prepare hardcopies. If this system can be utilized optimally, then paper usage from research activities can be reduced by as much as 699,282 sheets per year.

\subsubsection{Survey results from student samples}

- Lectures

The survey results show that paper use in face-to-face activities is extremely varied, ranging from 3-1000 sheets (left figure). However, by removing outliers, it can be estimated 
that the average paper usage for a lecture material per person is 50 sheets. Coupled with assignments and notes, it is estimated to reach around 111.51 sheets/person/subject.
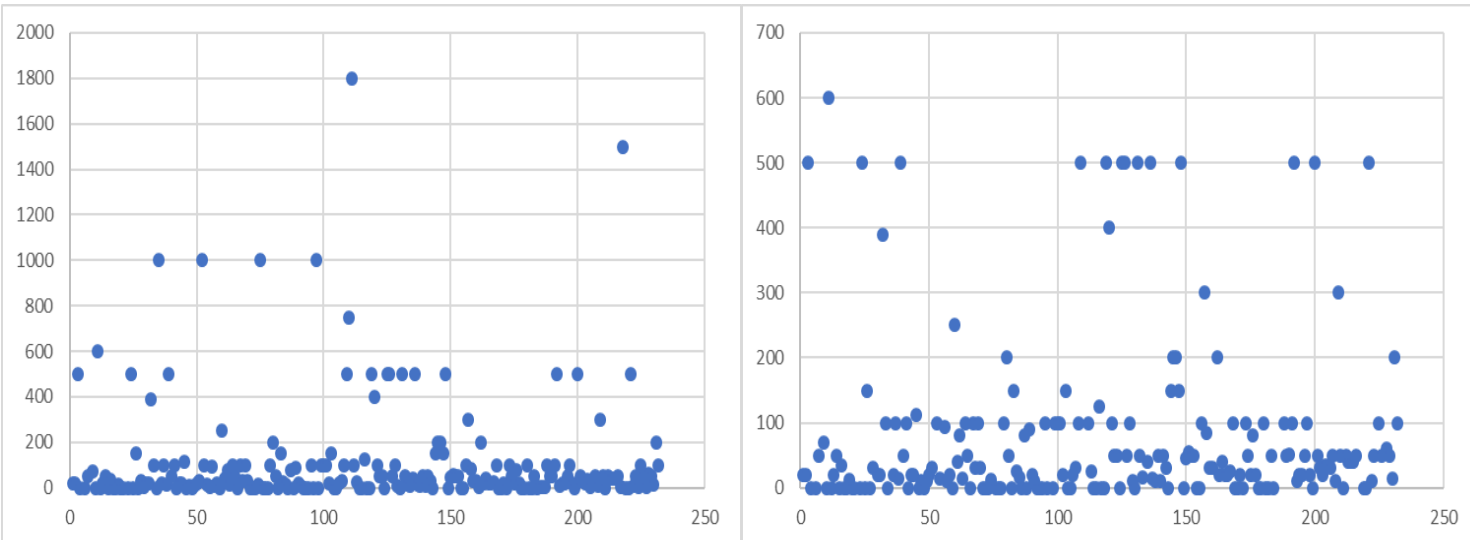

Figure 5. Paper usage (left: all samples, right: outlier removal) in face-to-face activities

Using survey results from lecturers and students, with an average of 24 credits per semester and 3 credits per course, it is found that the average number of courses taken per semester is 8 . In online lectures, all materials are shared in soft copies. With an average number of students of 40,595/year (total USU students in $2018=43,776$ and $2019=$ 37,415 ), the amount of paper that can be reduced every year ( 2 semesters) is $111.51 \mathrm{x}$ $40,595 \times 2 \times 8=69,753,021$ sheets per year.

\section{- Thesis completion}

The survey results show that the amount of paper used in thesis drafts vary greatly, ranging from 5 to 2500 sheets from proposal to defence (left picture). By removing outliers, it was found that the most common paper usage ranges from 10-500 sheets, averaging at 108.41 sheets/draft/ student.
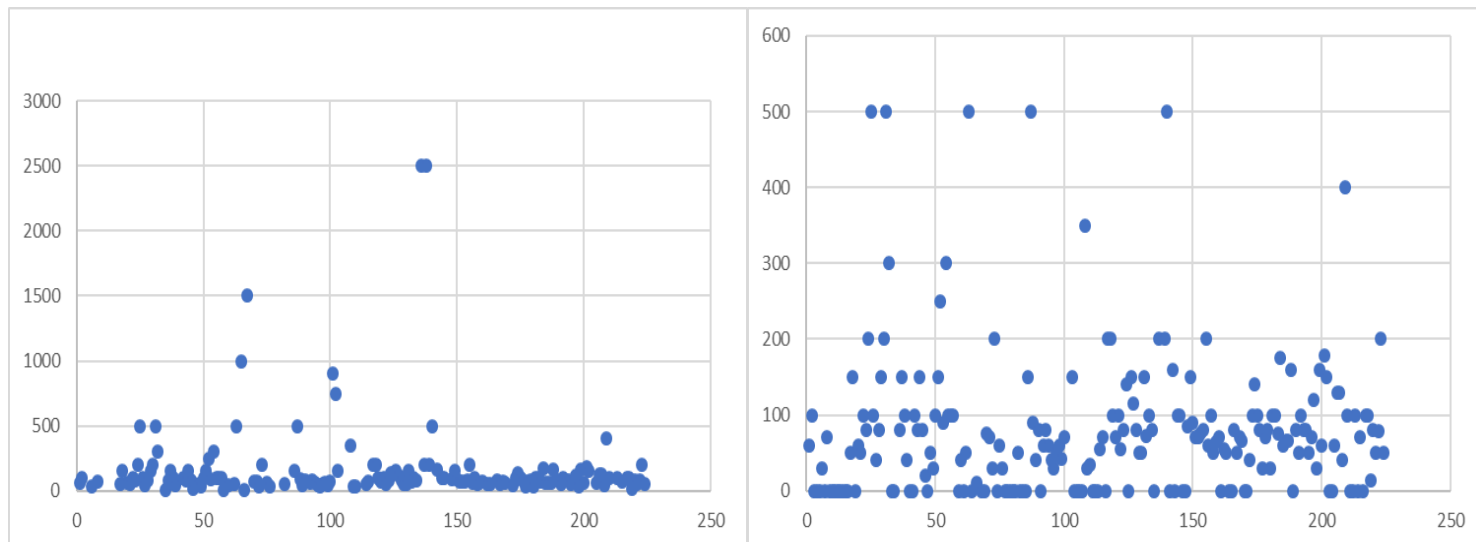

Figure 6. Paper usage for each thesis draft (left: all samples, right: outlier removal) in faceto-face activities 

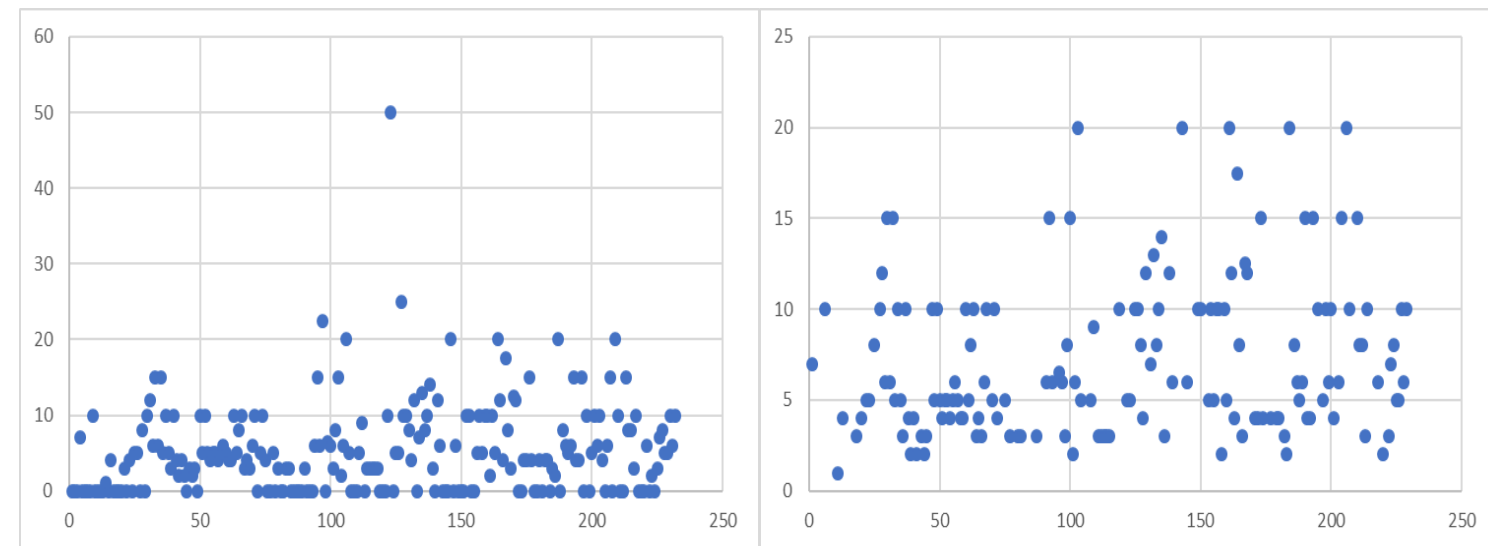

Figure 7. Total Revision (left: all samples, right: outlier removal) in face-to-face activities

The survey results show that the total amount of thesis drafts is somewhat varied, ranging from 1 to 50 revisions during the proposal up to the defence (left picture). By removing outliers, the most common number of revisions range between 1 - 20 times, averaging at 7.2 .

The average number of students undertaking a thesis each year can be estimated from the number of graduates, which is 2000-3000 people per graduation with an average of 2500 graduates. With 4 graduations per year, it can be estimated that the amount of paper used for the advising process per year is $108.415 \times 7.2 \times 2500 \times 4=7,809,076$ sheets per year.

\subsection{Obstacles encountered}

The obstacles of E-learning can be grouped into individual and institutional obstacles. Individual obstacles include lecturer and/or student competence, gadget ownerships and funding, institutional obstacles consists of person in charge competence, internet connection and policy support. In particular, these include:

1. Sub-par facilities (bad internet)

2. Teaching methods (material and delivery) that are still the same as face-to-face methods

3. Suboptimal efforts from lecturers and students (less intensive, difficult to understand, boring, piling up of assignments)

4. Income level to support gadget and internet costs

\subsection{Effectiveness of online methods}

- Lectures

Figure 6 shows that online methods have been successfully implemented in all faculties in USU. However, there are contrasting results from the two methods, where online effectiveness is still very low. 


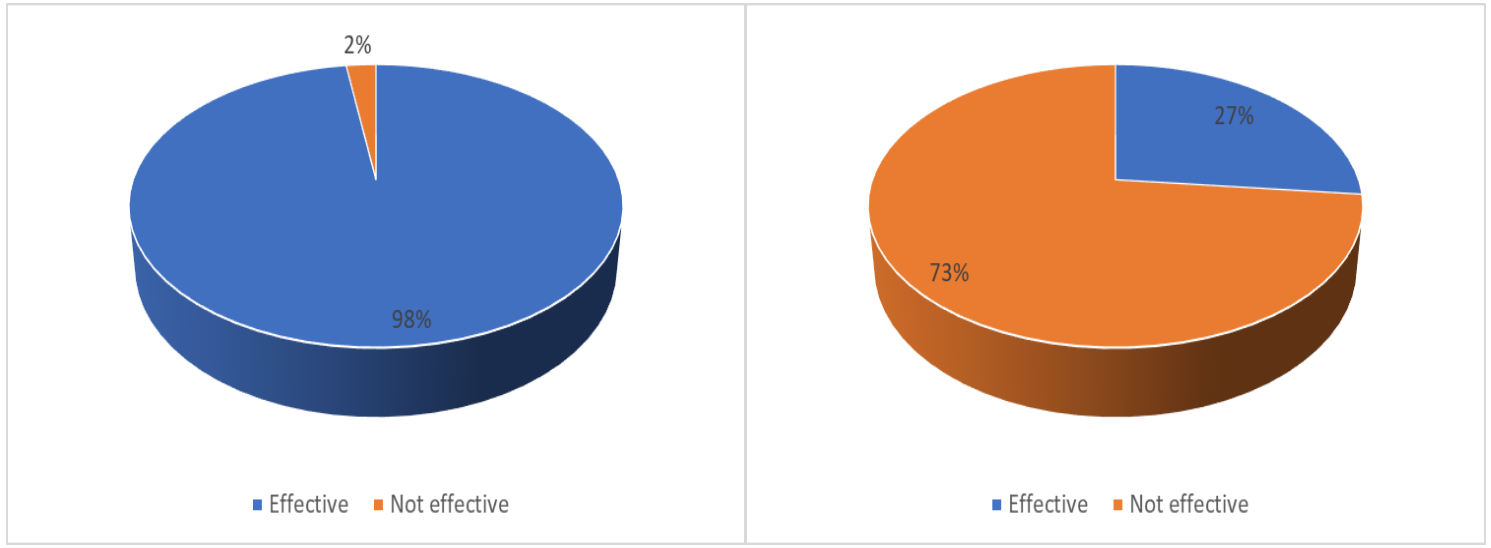

Figure 8. Performance of face-to-face (left) and online (right) methods

\section{- Thesis completion}
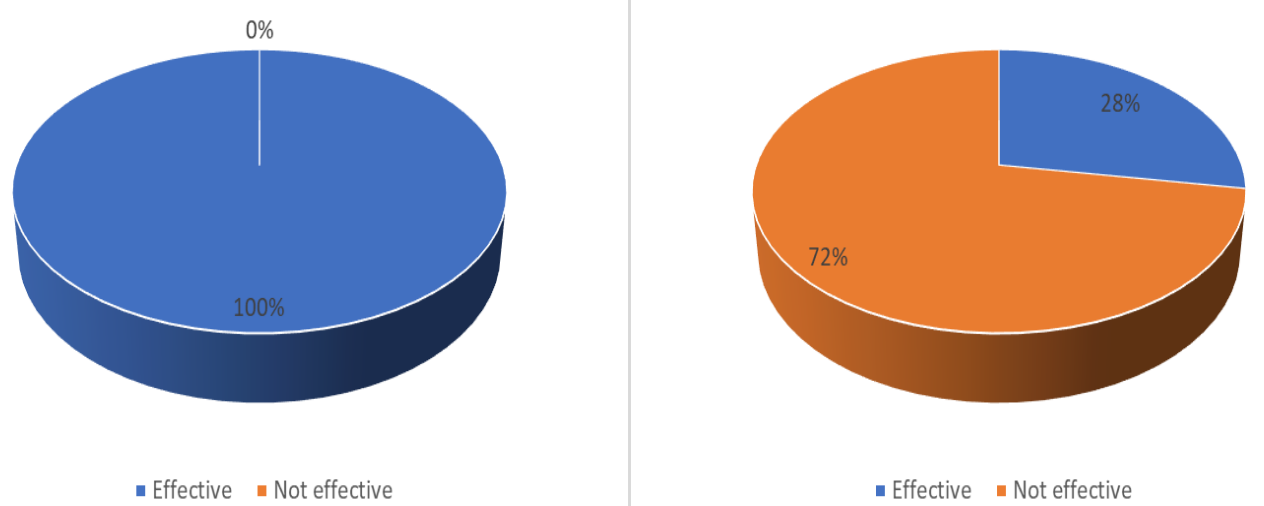

Figure 9. Effectiveness of face to face (left) and online (right) thesis completions

\section{Conclusion}

From the above information, it can be estimated that paper usage can be reduced by $78,261,379$ sheets per year, broken down into 699,282 from research activities of lecturers, $69,753,021$ from lectures and 7,809,076 from thesis completion. If one tree can be converted to 12,000 sheets of paper, then $48,040,000$ sheets are equivalent to 6,522 trees. If the average number of forest stand is about 91 stems/ha [5], then 6,522 trees are equivalent to an area of about 72 ha.

\section{Program Proposal}

Online methods have proven to be significant in reducing paper usage, albeit with a less effective learning outcome than face-to-face methods. Several obstacles that need to be overcome to ensure an equal or even higher learning outcome than face-to-face methods are:

1. Improvement of internet facilities in each faculty

2. Improvement of access to online learning facilities for every active USU student

3. Training on the use of online facilities for USU lecturers and students

4. Training in creating lecture material appropriate for online methods for USU lecturers 


\section{References}

1. Martin, J., Haggith, M., 2018. The State of the Global Paper Industry: Shifting Seas: New Challenges and Opportunities for Forests, People and the Climate, Environmental Paper Network

2. Asian Review, 2020. Pandemic shreds office paper demand as global telework unfolds. Available online at https://asia.nikkei.com/Business/Markets/Commodities/Pandemicshreds-office-paper-demand-as-global-telework-unfolds, tanggal 10/09/2020

3. Wright, T.S.A., 2009. Sustainability, internationalization, and higher education. New Directions for Teaching and Learning, Volume 2009, No. 118, pp. 105-115.

4. Cunningham, H., 2012. Partneringforpaperreduction. Feliciter, Volume 58, No.1, p.18.

5. Putra, A.T., 2015. Analisa Potensi Tegakan Hasil Inventarisasi Hutan di KPHP Model Berau Barat. Jurnal AGRIFOR, Volume XIV, Nomor 2, Oktober 2015. 